\title{
Allergic Sensitization at School Age is a Systemic Low-grade Inflammatory Disorder
}

Chawes, B. L.; Stokholm, J.; Schoos, A.-M. M.; Fink, N. R.; Pedersen, Susanne Brix; Bisgaard, H.

Published in:

Allergy

Link to article, DOI:

10.1111/all.13108

Publication date:

2017

Document Version

Peer reviewed version

Link back to DTU Orbit

Citation (APA):

Chawes, B. L., Stokholm, J., Schoos, A-M. M., Fink, N. R., Pedersen, S. B., \& Bisgaard, H. (2017). Allergic Sensitization at School Age is a Systemic Low-grade Inflammatory Disorder. Allergy, 72(7), 1073-1080. https://doi.org/10.1111/all.13108

\section{General rights}

Copyright and moral rights for the publications made accessible in the public portal are retained by the authors and/or other copyright owners and it is a condition of accessing publications that users recognise and abide by the legal requirements associated with these rights.

- Users may download and print one copy of any publication from the public portal for the purpose of private study or research.

- You may not further distribute the material or use it for any profit-making activity or commercial gain

- You may freely distribute the URL identifying the publication in the public portal 
Received Date : 11-Mar-2016

Revised Date : 26-Sep-2016

Accepted Date : 13-Dec-2016

Article type : Original Article: Experimental Allergy and Immunology

\section{Allergic Sensitization at School Age is a Systemic Low-grade Inflammatory Disorder}

Authors: Bo Lund Chawes, MD, PhD, DMSc ${ }^{1}$; Jakob Stokholm MD, $\mathrm{PhD}^{1+2}$; Ann-Marie

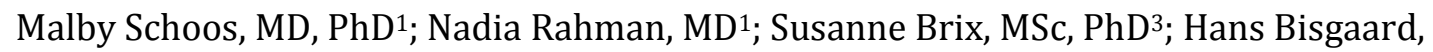
MD, DMSc ${ }^{1}$

\section{Affiliations:}

(1) COPSAC, Copenhagen Prospective Studies on Asthma in Childhood, Herlev and Gentofte Hospital, University of Copenhagen, Copenhagen; Denmark.

(2) Department of Pediatrics, Naestved Hospital, Naestved; Denmark.

(3) Center for Biological Sequence Analysis, Department of Systems Biology, Technical University of Denmark; Lyngby; Denmark

\section{Corresponding author:}

Professor Hans Bisgaard, MD, DMSc

Copenhagen Prospective Studies on Asthma in Childhood, Herlev and Gentofte Hospital, University of Copenhagen, Ledreborg Alle 34, DK-2820 Gentofte, Denmark

Tel: +4539777360

Fax: +4539777129

E-mail: bisgaard@copsac.com

Website: www.copsac.com

Online Repository: This article has an online data supplement.

Running Head: Allergic Sensitization and Systemic Low-grade Inflammation

Key words: Allergy, Children, high-sensitivity C-reactive protein, pro-inflammatory cytokines.

This article has been accepted for publication and undergone full peer review but has not been through the copyediting, typesetting, pagination and proofreading process, which may lead to differences between this version and the Version of Record. Please cite this article as doi: 10.1111/all.13108

This article is protected by copyright. All rights reserved. 


\section{ABBREVIATIONS}

COPSAC $_{2000}=$ COpenhagen Prospective Studies on Asthma in Childhood

CXCL8 $=$ Chemokine $(\mathrm{C}-\mathrm{X}-\mathrm{C}$ motif $)$ ligand 8

hs-CRP = high-sensitivity $\mathrm{C}$-reactive protein

IL-1 $\beta=$ Interleukin- $1 \beta$

IL-6 = Interleukin-6

$\mathrm{NCD}=$ non communicable disease

TNF- $\alpha=$ tumor necrosis factor $-\alpha$

$\mathrm{PCA}=$ principle component analysis

\section{ABSTRACT (248 words)}

\section{Background}

Systemic low-grade inflammation has been demonstrated in a range of the frequent noncommunicable diseases (NCDs) proposing a shared mechanism, but is largely unexplored in relation to allergic sensitization. We therefore aimed to investigate the possible association with childhood allergic sensitization.

\section{Methods}

High sensitivity C-reactive protein (hs-CRP), interleukin-1 $\beta$ (IL-1 $\beta$ ), IL-6, tumor necrosis factor- $\alpha$ (TNF- $\alpha$ ) and chemokine (C-X-C motif) ligand 8 (CXCL8) were measured in plasma at age $6 \mathrm{mo}(\mathrm{N}=214)$ and $7 \mathrm{yrs}(\mathrm{N}=277)$ in children from the Copenhagen Prospective Studies on Asthma in Childhood $2000\left(\right.$ COPSAC $\left._{2000}\right)$ birth cohort. Allergic sensitization against common inhalant and food allergens was determined longitudinally at age $1 / 2,1 \frac{1}{2}, 4$ and $6 y$ rs by specific-IgE assessments and skin prick tests. Associations between inflammatory biomarkers and sensitization phenotypes were tested with logistic regression and principle component analyses (PCA).

Results

Adjusted for gender, recent infections and a CRP genetic risk-score, hs-CRP at 7yrs was associated with concurrent elevated specific-IgE against any allergen (adjusted OR $(\mathrm{aOR})=1.40 ; 95 \% \mathrm{CI}, 1.14-1.72 ; \mathrm{p}=0.001$ ), aeroallergens (aOR, 1.43; 1.15-1.77; $\mathrm{p}=0.001$ ), food allergens (aOR, 1.31; 95\% CI, 1.02-1.67; $\mathrm{p}=0.04$ ), sensitization without any clinical allergy symptoms $(\mathrm{aOR}=1.40 ; 1.06-1.85 ; \mathrm{p}=0.02)$, and with similar findings for skin prick tests. The other inflammatory markers were not univariantly associated with sensitization, but multi-parametric PCA suggested a specific inflammatory response among sensitized children. Inflammatory markers at age $6 \mathrm{mo}$ were not associated with subsequent development of sensitization phenotypes.

\section{Conclusions}

Elevated hs-CRP is associated with allergic sensitization in school-aged children suggesting systemic low-grade inflammation as a phenotypic characteristic of this early onset NCD. 


\section{INTRODUCTION}

Chronic noncommunicable diseases (NCDs) encompass cardiovascular diseases, metabolic diseases, cancer, and chronic lung diseases. The earliest debuting NCDs are childhood asthma and allergy (1) and while asthma is usually considered part of chronic lung diseases, childhood allergy is vastly neglected in NCD research.

The growing burden of NCDs is a major global health threat (2) but despite decades of intensive research identifying preventive measures has largely failed, which may be due to a far too disease-specific approach rather than exploring common features and mechanisms in the origins of NCDs. Recent findings pinpoint that chronic low-grade inflammation is a common nominator of virtually all NCDs (3), which is reflected by elevated levels of C-reactive protein measured by high-sensitivity assays (hs-CRP) in highly endemic societies (4) and accompanying the specific disorders like cardiovascular disease (5), diabetes mellitus (6), chronic obstructive pulmonary disease (7) and asthma (8). However, only very few studies have investigated whether childhood allergic sensitization is also characterized by systemic low-grade inflammation.

The objective of this work was therefore to investigate whether a systemic low-grade inflammatory process is present in young children with allergic sensitization based on data from the Copenhagen Prospective Studies on Asthma in Childhood 2000 (COPSAC 2000 ) birth cohort (9). For that purpose, we measured plasma levels of hs-CRP along with secondary assessments of related inflammatory biomarkers including interleukin 6 (IL6), IL-1 $\beta$, tumor necrosis factor (TNF)- $\alpha$ and chemokine (C-X-C motif) ligand 8 (CXCL8, formerly IL-8) at age 6 months and 7 years and investigated the possible association with allergic sensitization and rhinitis during pre-school age.

\section{METHODS}

\section{The COPSAC 2000 Birth Cohort}

The participants comprised 411 children of the at-risk COPSAC 2000 prospective birth cohort study born to mothers with physician-diagnosed asthma (9). The children were enrolled at age 4 weeks and subsequently attended the COPSAC single-center clinical research unit for scheduled clinical investigations at 6-monthly intervals until age 7 years as well as immediately upon onset of any respiratory-, allergy- or skin-related symptoms (10-12). The pediatricians employed at the research unit acted as primary practitioners for the cohort children and were the only ones responsible for the diagnosis and treatment of asthma, allergy, and eczema in these children.

The study was conducted in accordance with the Declaration of Helsinki and was approved by the Local Ethics Committee (KF 01-289/96), and the Danish Data Protection Agency (2008-41-1754). Both parents gave oral and written informed consent before enrolment. 


\section{Inflammatory Biomarkers}

At age 6 months and 7 years, venous blood was sampled, centrifuged to separate plasma from plasma cells, and immediately stored at $-80^{\circ} \mathrm{C}$ until analysis. The samples were transported on dry ice to the laboratory, where levels of inflammatory biomarkers were determined by high-sensitivity ELISA assays based on electro-chemiluminescence in a 4plex setting for IL-1 $\beta$, IL-6, CXCL8 and TNF- $\alpha$ and as a single high-sensitivity assay from MesoScale Discovery for hs-CRP. The LLOD was $0.005 \mathrm{ng} / \mathrm{mL}$. Samples were read in duplicates with the Sector Imager 6000 (MesoScale Discovery®, Gaithersburg, MD, USA). The limit of detection (mean signal from blanks +3SD) was $9.54 \mathrm{pg} / \mathrm{mL}$ for hs-CRP, $0.15 \mathrm{pg} / \mathrm{mL}$ for IL-1 $\beta, 0.17 \mathrm{pg} / \mathrm{mL}$ for IL-6, $0.09 \mathrm{pg} / \mathrm{mL}$ for CXCL8 and $0.08 \mathrm{pg} / \mathrm{mL}$ for TNF- $\alpha$.

We chose to investigate hs-CRP as this is a well-established measure of non-specific lowgrade inflammation in previous NCD studies (3). The additional biomarkers were chosen to enable a biological validation of the hs-CRP levels, i.e. IL-6 triggers CRP release from the liver and should be associated with CRP whereas CXCL8 is not directly related to CRP release.

\section{Allergic Sensitization}

Allergic sensitization was assessed longitudinally at ages 6 months, 18 months, 4 years and 6 years by specific-IgE levels in serum and skin prick tests.

Specific-IgE levels in serum were measured against 16 common inhalant and food allergens (cat, dog, horse, birch, timothy grass, mugwort, house dust mites, moulds, hen's egg, cow's milk, fish, wheat, peanut, soybean, shrimp) by ImmunoCAP assay (Pharmacia Diagnostics AB, Uppsala, Sweden) (13). Allergic sensitization was defined as specific-IgE $\geq 0.35 \mathrm{kU} / \mathrm{L}(14)$.

Skin prick test was performed using standard allergen extracts (ALK Abello, Soluprick ${ }^{\circledR}$ SQ, Hørsholm, Denmark) of 14 common allergens (cat, dog, horse, birch, timothy grass, mugwort, house dust mite, moulds, egg, milk, fish, wheat, peanut, soybean) and with fresh cow's milk and pasteurized hen's egg (15). Droplets of allergen extracts, fresh foods and controls were applied to the child's volar forearm and a sterile lancet was used to prick through the droplets penetrating the skin barrier. The reaction was noted after 15 minutes and a positive test was defined as a wheal diameter $\geq 2 \mathrm{~mm}$ larger than the negative control (physiological sodium chloride, $9 \mathrm{mg} / \mathrm{mL}$ ) at ages 6 and 18 months and $\geq 3 \mathrm{~mm}$ at ages 4 and 6 years.

Children did not use anti-histamines within 72 hours of testing, mild steroid creams (group 1-2) on the arms 24 hours before testing or stronger steroid creams (group 3-4) 14 days before testing.

Allergic sensitization diagnosed from specific-IgE or skin prick test was analyzed as sensitization to (1) any allergen, (2) any aeroallergen, (3) any food allergen, and (4) any allergen without accompanying symptoms, i.e. sensitization without asthma, rhinitis, food reactions or eczema. 


\section{Allergic Rhinitis}

Allergic rhinitis was diagnosed at age 7 years by the COPSAC pediatricians based on interviews with the parents on history of symptoms in the child's $7^{\text {th }}$ year of life. Rhinitis was defined as troublesome sneezing or blocked or runny nose in the past 12 months in periods without concurrent cold or flu $(16,17)$.

Total-IgE

Total-IgE level was measured at age 6 years by ImmunoCAP (Pharmacia Diagnostics AB, Uppsala, Sweden) with a detection limit of $2 \mathrm{kU} / \mathrm{l}$.

\section{Covariates}

Covariates in relation to hs-CRP levels at age 7 years included gender; tobacco smoke exposure (parental smoking in the home at age 7 years [yes/no]); yearly household income (low [<53.000 €], medium [53.000-80.000 €], high [>80.000 €]); and infections 14 days prior to biomarker assessment (upper and lower respiratory tract infections, gastroenteritis or fever with unknown cause [yes/no]). Furthermore, a CRP genetic riskscore was calculated based on 17 single nucleotide variants known to be related to CRP levels (18) with the score constructed as the sum of risk alleles weighted on their published effect size and subsequent transformed to z-scores (19).

\section{Statistics}

Inflammatory biomarker values below detection limit were set to half of the lowest value detected for the specific biomarker. Values were log-transformed, and the mean of the duplicate measurements were used for association analyses. Zero individuals had duplicate measures below LLOD.

Associations between continuous inflammatory biomarker levels and concurrent binary allergy outcomes were tested by conventional statistics with logistic regression, whereas the association with total-IgE was analyzed by linear regression. The association between biomarker levels at age 6 months and subsequent development of allergy outcomes during preschool-age was tested by logistic generalized estimations equations (GEE) utilizing the repeated subject assessments at all four age-points (6 months, 18 months, 4 years and 6 years).

We also applied an unsupervised pattern recognition and dimensional reduction principal component analysis (PCA) for inflammatory biomarker levels at age 7 years. The PCA approach included extraction of underlying orthogonal components that described the systematic part of the variation across the biomarkers using centered and scaled mediator levels.

All results were presented as odds ratios with 95\% CI. Analyses utilizing mediator levels at age 7 years were adjusted for covariates associated with levels of hs-CRP using a cutoff at $\mathrm{p} \leq 0.10$. Analyses utilizing mediator levels at age 6 months were adjusted for siblings, infections 14 days prior to and wheeze at any time prior to mediator assessment, as we recently demonstrated an association between those covariates and hs-CRP at age 6 months in our cohort (20). All analyses were done using SAS version 9.3 (SAS Institute, Cary, NC).

Additional details are outlined in the Online Repository. 


\section{RESULTS}

\section{Baseline Characteristics}

After completion of the 7-year follow-up, hs-CRP, IL-1 $\beta$, IL-6, TNF- $\alpha$ and CXCL8

were available for 277 (67\%) of the 411 children in the cohort. Children with

available biomarker assessments at age 7 years compared to children without

assessments tended to come from families with higher household income $(p=0.06)$,

but showed no other differences in baseline characteristics or asthma, allergy or

eczema prevalence (Table E1). Of the 277 children with mediator levels available at

age 7 years, 214 also had levels measured at age 6 months.

Plasma levels of hs-CRP, IL-6, TNF- $\alpha$ and CXCL8 were within the expected range at both age-points, whereas IL-1 $\beta$ levels were much lower than expected(21) with null values for $118(43 \%)$ at age 7 years and 52 (24\%) at age 6 months (Table E2). Therefore, IL-1 $\beta$ was not included in the association analyses. IL- 6 and hs-CRP levels were strongly positively correlated ( $\mathrm{p}<0.001)$, whereas TNF- $\alpha$ and CXCL8 levels were not significantly correlated with hs-CRP ( $\mathrm{p}$-values $\geq 0.32$ ).

Determinants of $h s-C R P$ at age 7 years

Girls had significantly higher hs-CRP levels compared to boys: median hs-CRP level 4.02 $\mathrm{mg} / \mathrm{L}$ (IQR, 1.82-14.62) vs. $1.92 \mathrm{mg} / \mathrm{L}$ (0.82-6.56), $\mathrm{p}=0.0004$, and hs-CRP was increased in children with an infectious episode within 14 days prior to biomarker assessment: $24.19 \mathrm{mg} / \mathrm{L}$ (4.32-33.51) vs. $2.73 \mathrm{mg} / \mathrm{L}$ (1.16-7.50), $\mathrm{p}<0.0001$. Household income and tobacco smoke exposure in the home were not associated with hs-CRP levels (Table 1). Based on these findings, we adjusted association analyses utilizing hs-CRP at age 7 years for gender and infections.

\section{CRP Genetic Risk-score}

The genetic CRP risk-score was linearly associated with hs-CRP levels at 6 months ( $\beta$ coefficient +0.27 per $\mathrm{z}$-score increase; $95 \% \mathrm{CI}, 0.13-0.41 ; \mathrm{p}=0.0002$ ) and hs-CRP levels at age 7 years ( $\beta$-coefficient +0.24 per $z$-score increase; $0.03-0.44 ; p=0.02$ ). Based on that, association analyses utilizing hs-CRP at age 6 months and 7 years were additionally adjusted for the genetic CRP risk-score. However, the CRP risk-score was not associated with the outcomes of interest, e.g. any sensitization determined by specific-IgE at age 7 years: OR, 0.97; 95\% CI, 0.76-1.24; $\mathrm{p}=0.82$.

\section{Inflammatory Biomarkers at 7 years vs. Concurrent Allergy Endpoints}

Specific-IgE: hs-CRP was positively associated with presence of any sensitization (adjusted OR (aOR), 1.40; 1.14-1.72; $\mathrm{p}=0.001$ ), aeroallergen sensitization (aOR, 1.43; 1.15-1.77; $\mathrm{p}=0.001$ ), and food sensitization ( $\mathrm{aOR}, 1.31$; 1.02-1.67; $\mathrm{p}=0.04)$. Elevated hsCRP even increased the risk of allergic sensitization among children without any clinical allergy manifestations (asymptomatic sensitization): aOR, 1.40; 1.06-1.85; $\mathrm{p}=0.02$. 
Skin prick test: Similarly, increasing hs-CRP level increased the risk of any sensitization (aOR, 1.50; 1.18-1.92; $\mathrm{p}=0.001$ ), aeroallergen sensitization (aOR, 1.49; 1.16-1.90; $\mathrm{p}=0.002$ ), food sensitization (aOR, 1.66; 1.05-2.63; $\mathrm{p}=0.03$ ) and asymptomatic sensitization (aOR, 1.70; 1.07-2.70; $\mathrm{p}=0.03$ ) diagnosed from skin prick tests.

Allergic rhinitis: Elevated hs-CRP level was significantly associated with increased risk of allergic rhinitis: aOR, 1.36; 1.05-1.76; $p=0.02$ (Table 2). Median hs-CRP levels in children with and without rhinitis and the different sensitization phenotypes are depicted in Figure 1.

Asthma: Level of hs-CRP was also positively associated with an increased risk of current asthma: aOR, $1.37 ; 1.03-1.84 ; \mathrm{p}=0.03$.

Total-IgE: hs-CRP and total-IgE levels were positively linearly associated: adjusted $\beta$ coefficient, $0.15 ; 0.03-0.26 ; \mathrm{p}=0.01$.

We found no univariate associations between IL-6, TNF- $\alpha$ or CXCL8 levels and any of the above endpoints (Table 2).

Unadjusted models revealed similar results and are shown in Table E3 Online.

Furthermore, a sensitivity analysis excluding the 24 children with an infectious episode prior to the biomarker assessments showed comparable associations and significance levels (Table E4 Online).

\section{Principle Component Analysis}

An unsupervised multi-parametric PCA showed that hs-CRP, IL-6, TNF- $\alpha$ and CXCL8 at age 7 years were all positively correlated in the first principal component $\left(\mathrm{PC}_{1}\right)$ explaining $36 \%$ of the variation in the data, whereas $27 \%$ of the variation was explained by $\mathrm{PC}_{2}$, which separated hs-CRP and IL-6 from TNF- $\alpha$ and CXCL8 (Figure 2). PC 1 yielded increased odds ratios for all the allergic sensitization phenotypes, allergic rhinitis and asthma, but the association was only statistically significant for asthma $(\mathrm{p}=0.03) . \mathrm{PC}_{2}$ was significantly associated with any positive skin prick test $(\mathrm{p}=0.02)$, allergic rhinitis $(p=0.03)$, and showed a trend of association with several of the other phenotypes (Table 3).

Inflammatory Biomarkers at 6 months vs. Development of Allergy Endpoints We did not detect any relationship between hs-CRP, IL-6, TNF- $\alpha$ or CXCL8 and concurrent allergic sensitization at age 6 months diagnosed from either sIgE $(\mathrm{N}=22$ cases) or skin prick test ( $\mathrm{N}=21$ cases). Accordingly, a Generalised Estimating Equation (GEE) model including sensitization data from ages 6 months, 18 months, 4 years and 6 years did not show any associations between inflammatory biomarkers at age 6 months and subsequent development of sensitization against any airborne or food allergens during preschool age (Table E5 Online). 


\section{DISCUSSION}

Principle Findings

Allergic sensitization at school age is characterized by elevated hs-CRP level independently of allergen type or concurrent clinical allergy manifestations suggesting the presence of an active systemic inflammatory process in allergic sensitization similar to other NCDs.

\section{Strengths and Limitations of the Study}

A major strength of this study is the comprehensive standardized objective assessments and clinical diagnoses performed solely by the research pediatricians at our singlecenter site in rigorous accordance with predefined algorithms. This approach allowed analyses of symptomatic and asymptomatic sensitization as well as analyses of different sensitization phenotypes.

Consistent results across traditionally defined sensitization phenotypes and symptomatic vs. non-symptomatic disease enhance the confidence in the findings. Associations were most prominent for hs-CRP obtained by both conventional statistics and by the PCA approach, where $\mathrm{PC}_{2}$ associated with sensitization and separated hs-CRP and IL- 6 from TNF- $\alpha$ and CXCL8.

Another significant strength of the study is our ability to construct and adjust for a CRP genetic risk-score (18) as some loci affects both the development of asthma, sensitization and CRP levels $(22,23)$. The observed relationship between CRP levels and allergy-related outcomes could therefore be speculated to be due to pleiotropic gene effects and not the low grade inflammation itself (24). Our finding of a robust and unchanged association between sensitization and hs-CRP after adjusting for the CRP genetic risk-score argues against pleiotropic gene effects being responsible for the association.

In line with previous studies, we found that hs-CRP was elevated in girls (25), among asthmatics (26) and in subjects with a recent infectious episode (27), which serves as a biological validation of the data. Furthermore, hs-CRP levels were strongly linearly associated with IL-6, which is well known to trigger CRP release from the liver (28).

It is a limitation of the study that we could not detect a biologically meaningful signal from IL-1 $\beta$, which may be caused by a prolonged storage time and previous freeze-thaw cycles of the samples. IL- $1 \beta$ is known to be particular sensitive to freeze-thawing and degrades significantly over time, even at $-80{ }^{\circ} \mathrm{C}(29)$.

We did not detect an association between passive smoke exposure and CRP at age 7 years, which could be related to a lack of an objective assessment such as urinary, salivary or serum cotinine or nicotine levels at this age point.

Another limitation of the study is the high-risk nature of the cohort, as all the children are born to mothers with a history of asthma, which reduces generalizability of the findings. However, even though the high-risk of sensitization in the cohort may have influenced the measured biomarker levels, this should not diminish our ability to explore the association between allergic sensitization and biomarker levels within the 
cohort.

\section{Interpretation of the Findings}

This study shows an association between increasing levels of hs-CRP and allergic sensitization in 7-year-old children suggesting that the propensity to develop elevated levels of specific-IgE antibodies is a systemic low-grade inflammatory disorder.

Elevated hs-CRP was present in children with allergic sensitization irrespective of allergen type or combination of specific sensitizations and thus not a specific characteristic of food or aeroallergen sensitization. This implies that low-grade inflammation in children with allergic sensitization is a common host feature rather than a disease specific trait. Such interpretation is supported by the association between hs-CRP and specific-IgE levels even in asymptomatic children and the association with total-IgE suggesting that low-grade inflammation may characterize children with poor immune regulation rather than children with symptomatic vs. asymptomatic disease. Unfortunately, the lack of association between low-grade inflammation at age 6 months and subsequent development of sensitization implies that hs-CRP cannot be utilized as a predictive biomarker.

In line with our findings, specific-IgE data from 2-19 year-old children and adolescents $(\mathrm{N}=4,111)$ participating in the US National Health and Nutrition Examination Survey 20052006 (NHANES) showed elevated hs-CRP in subjects with allergic sensitization (30). In contrast, another study of 131 children aged 6-18 years did not detect such association, but all the children had current asthma and were recruited from a tertiary pulmonary center (31), which may have impacted the analyses. The European multinational PASTURE (Protection against Allergy Study in Rural Environments) study group reported an inverse association between hs-CRP at age 1 year and allergic sensitization at age $4 \frac{1}{2}$ years among 636 children (32). We could not detect an association between hs-CRP levels at age 6 months and subsequent development of sensitization during preschool age, but comparability between our and the PASTURE study findings is limited as half of the population in the PASTURE study is from farming environments, which may affect both the level of low-grade inflammation and risk of sensitization. Besides these three studies, we are not aware of additional analyses of the interrelationship between hs-CRP and allergic phenotypes.

The observed association between hs-CRP and sensitization may be interpreted as allergic sensitization being a systemic inflammatory disorder rather than an isolated Thelper 2-driven immune response. In support of this theory, cytokines and chemokines originating from the allergic cascade have been shown to trigger recruitment of inflammatory progenitor cells from the bone marrow as a possible systemic immuneinflammatory pathway (33). Local production of IL- 6 and TNF- $\alpha$ triggering CRP release from the liver or possibly IL-1 $\beta$-related inflammasome activation in tissue macrophages could also contribute to sustained elevation of CRP and low-grade inflammation, as CRP is not cleared by binding to phosphocholine on microbes in the absence of an infection. Alternatively, systemic low-grade inflammation is not per se part of the allergic sensitization immune phenotype, but is indirectly linked to sensitization through shared environmental risk factors such as alterations of the human microbiome $(34,35)$ and changing dietary habits (36). 
A vicious cycle of sustained low-grade inflammation with elevated hs-CRP has now been demonstrated in NCDs emerging from virtually all organ systems (1) proposing an active inflammatory process as a common nominator of such disorders. This suggests a central role of the immune system not only in childhood allergic sensitization, but also in many other idiopathic immuno-inflammatory disorders which have increased in prevalence along with the global adaption of modern environmental and lifestyle changes (37). Strategies to restore the early life immunological health status such as high-dose vitamin D supplementation during pregnancy (38), may thus not only have the capacity to prevent development of allergic sensitization but potentially also prevent a range of other frequent NCDs warranting increased awareness of childhood allergy in future NCD research.

\section{Conclusion}

Allergic sensitization in school-aged children of the Danish COPSAC 2000 at-risk birth cohort is associated with elevated hs-CRP suggesting systemic low-grade inflammation as a phenotypic characteristic of childhood sensitization.

\section{ACKNOWLEDGEMENTS}

We gratefully express our gratitude to the children and families of the COPSAC 2000 cohort study for all their support and commitment. We acknowledge and appreciate the unique efforts of the COPSAC research team and technical assistance from Lisbeth Buus Rosholm, Systems Biology, Technical University of Denmark as well as Bjarne Kristensen and Inger Pedersen for their dedicated work with the IgE analyses.

\section{REFERENCES}

1. Prescott SL. Early-life environmental determinants of allergic diseases and the wider pandemic of inflammatory noncommunicable diseases. J Allergy Clin Immunol 2013;131:23-30.

2. Hanson M, Gluckman P. Developmental origins of noncommunicable disease: population and public health implications. Am J Clin Nutr 2011;94:1754S-1758S.

3. Renz H, von Mutius E, Brandtzaeg P, Cookson WO, Autenrieth IB, Haller D. Geneenvironment interactions in chronic inflammatory disease. Nat Immunol 2011;12:273-277.

4. McDade TW. Early environments and the ecology of inflammation. Proc Natl Acad Sci U S A 2012;109 Suppl 2:17281-17288.

5. Sabatine MS, Morrow DA, Jablonski KA, Rice MM, Warnica JW, Domanski MJ et al. Prognostic significance of the Centers for Disease Control/American Heart Association high-sensitivity C-reactive protein cut points for cardiovascular and other outcomes in patients with stable coronary artery disease. Circulation 2007;115:1528-1536. 
6. Hung M-J, Hsu K-H, Hu W-S, Chang N-C, Hung M-Y. C-reactive protein for predicting prognosis and its gender-specific associations with diabetes mellitus and hypertension in the development of coronary artery spasm. PloS One 2013;8:e77655.

7. Thomsen M, Ingebrigtsen TS, Marott JL, Dahl M, Lange P, Vestbo J et al. Inflammatory biomarkers and exacerbations in chronic obstructive pulmonary disease. JAMA J Am Med Assoc 2013;309:2353-2361.

8. Takemura M, Matsumoto H, Niimi A, Ueda T, Matsuoka H, Yamaguchi M et al. High sensitivity C-reactive protein in asthma. Eur Respir J 2006;27:908-912.

9. Bisgaard H. The Copenhagen Prospective Study on Asthma in Childhood (COPSAC): design, rationale, and baseline data from a longitudinal birth cohort study. Ann Allergy Asthma Immunol Off Publ Am Coll Allergy Asthma Immunol 2004;93:381389.

10. Bisgaard H, Hermansen MN, Loland L, Halkjaer LB, Buchvald F. Intermittent inhaled corticosteroids in infants with episodic wheezing. N Engl J Med 2006;354:19982005.

11. Bisgaard H, Hermansen MN, Buchvald F, Loland L, Halkjaer LB, Bønnelykke K et al. Childhood asthma after bacterial colonization of the airway in neonates. $N$ Engl J Med 2007;357:1487-1495.

12. Bisgaard H, Pipper CB, Bønnelykke K. Endotyping early childhood asthma by quantitative symptom assessment. J Allergy Clin Immunol 2011;127:1155-1164.e2.

13. Chawes BLK, Bønnelykke K, Bisgaard H. Elevated eosinophil protein X in urine from healthy neonates precedes development of atopy in the first 6 years of life. $\mathrm{Am} \mathrm{J}$ Respir Crit Care Med 2011;184:656-661.

14. Ballardini N, Nilsson C, Nilsson M, Lilja G. ImmunoCAP Phadiatop Infant--a new blood test for detecting IgE sensitisation in children at 2 years of age. Allergy 2006;61:337-343.

15. Schoos A-MM, Chawes BLK, Følsgaard N, Samandari N, Bønnelykke K, Bisgaard H. Disagreement Between Skin Prick Test and Specific IgE in Young Children. Allergy Published Online First: 16 September 2014. doi:10.1111/all.12523

16. Chawes BLK, Kreiner-Møller E, Bisgaard H. Objective assessments of allergic and nonallergic rhinitis in young children. Allergy 2009;64:1547-1553.

17. Chawes BLK, Bønnelykke K, Kreiner-Møller E, Bisgaard H. Children with allergic and nonallergic rhinitis have a similar risk of asthma. J Allergy Clin Immunol 2010;126:567-573-8.

18. Dehghan A, Dupuis J, Barbalic M, Bis JC, Eiriksdottir G, Lu C et al. Meta-analysis of genome-wide association studies in $>80000$ subjects identifies multiple loci for Creactive protein levels. Circulation 2011;123:731-738.

19. Kreiner-Møller E, Bisgaard H, Bønnelykke K. Prenatal and postnatal genetic influence on lung function development. J Allergy Clin Immunol 2014;134:10361042.e15.

20. Chawes BLK, Stokholm J, Bønnelykke K, Brix S, Bisgaard H. Neonates with reduced neonatal lung function have systemic low-grade inflammation. J Allergy Clin 
Immunol 2015;135:1450-1456.e1.

21. Jackman RP, Utter GH, Heitman JW, Hirschkorn DF, Law JP, Gefter N et al. Effects of blood sample age at time of separation on measured cytokine concentrations in human plasma. Clin Vaccine Immunol CVI 2011;18:318-326.

22. Bønnelykke K, Matheson MC, Pers TH, Granell R, Strachan DP, Alves AC et al. Metaanalysis of genome-wide association studies identifies ten loci influencing allergic sensitization. Nat Genet 2013;45:902-906.

23. Hinds DA, McMahon G, Kiefer AK, Do CB, Eriksson N, Evans DM et al. A genome-wide association meta-analysis of self-reported allergy identifies shared and allergyspecific susceptibility loci. Nat Genet 2013;45:907-911.

24. Solovieff N, Cotsapas C, Lee PH, Purcell SM, Smoller JW. Pleiotropy in complex traits: challenges and strategies. Nat Rev Genet 2013;14:483-495.

25. MacKenzie KE, Wiltshire EJ, Peña AS, Gent R, Hirte C, Piotto L et al. Hs-CRP is associated with weight, BMI, and female sex but not with endothelial function in children with type 1 diabetes. Pediatr Diabetes 2009;10:44-51.

26. PubMed entry. http://www.ncbi.nlm.nih.gov/pubmed/16707391 (accessed 15 Apr2014).

27. Pepys MB, Hirschfield GM. C-reactive protein: a critical update. J Clin Invest 2003;111:1805-1812.

28. Voleti B, Agrawal A. Regulation of basal and induced expression of C-reactive protein through an overlapping element for OCT-1 and NF-kappaB on the proximal promoter. J Immunol Baltim Md 1950 2005;175:3386-3390.

29. de Jager W, Bourcier K, Rijkers GT, Prakken BJ, Seyfert-Margolis V. Prerequisites for cytokine measurements in clinical trials with multiplex immunoassays. BMC Immunol 2009;10:52.

30. Visness CM, London SJ, Daniels JL, Kaufman JS, Yeatts KB, Siega-Riz A-M et al. Association of obesity with IgE levels and allergy symptoms in children and adolescents: results from the National Health and Nutrition Examination Survey 2005-2006. J Allergy Clin Immunol 2009;123:1163-1169, 1169-4.

31. Livnat G, Yoseph RB, Nir V, Hakim F, Yigla M, Bentur L. Evaluation of High-Sensitivity Serum CRP Levels Compared to Markers of Airway Inflammation and Allergy as Predictors of Methacholine Bronchial Hyper-Responsiveness in Children. Lung Published Online First: 21 October 2014. doi:10.1007/s00408-014-9658-6

32. Mustonen K, Orivuori L, Keski-Nisula L, Hyvärinen A, Pfefferle PI, Riedler J et al. Inflammatory response and IgE sensitization at early age. Pediatr Allergy Immunol Off Publ Eur Soc Pediatr Allergy Immunol 2013;24:395-401.

33. Holt PG, Sly PD. Interaction between adaptive and innate immune pathways in the pathogenesis of atopic asthma: operation of a lung/bone marrow axis. Chest 2011;139:1165-1171.

34. Bisgaard H, Bønnelykke K, Stokholm J. Immune-mediated diseases and microbial exposure in early life. Clin Exp Allergy J Br Soc Allergy Clin Immunol 2014;44:475481. 
35. Bisgaard H, Li N, Bonnelykke K, Chawes BLK, Skov T, Paludan-Müller G et al. Reduced diversity of the intestinal microbiota during infancy is associated with increased risk of allergic disease at school age.J Allergy Clin Immunol 2011;128:646-652.e5.

36. Prescott S, Nowak-Węgrzyn A. Strategies to prevent or reduce allergic disease. Ann Nutr Metab 2011;59 Suppl 1:28-42.

37. Bach J-F. The Effect of Infections on Susceptibility to Autoimmune and Allergic Diseases. $N$ Engl J Med 2002;347:911-920.

38. Chawes BL, Bønnelykke K, Stokholm J, Vissing NH, Bjarnadóttir E, Schoos A-MM et al. Effect of Vitamin D3 Supplementation During Pregnancy on Risk of Persistent Wheeze in the Offspring: A Randomized Clinical Trial. JAMA 2016;315:353-361.

\section{AUTHOR CONTRIBUTIONS}

The guarantor of the study is HB who has been responsible for the integrity of the work as a whole, from conception and design to conduct of the study and acquisition of data, analysis and interpretation of data and writing of the manuscript. BC, JS, AMS, NF and SB were responsible for data analysis, interpretation and writing the manuscript. $\mathrm{BC}$ wrote the first draft of the manuscript. SB was responsible for laboratory inflammatory mediator assessments. No honorarium, grant, or other form of payment was given to anyone to produce the manuscript. All co-authors have contributed substantially to the analyses and interpretation of the data, and have provided important intellectual input and approval of the final version of the manuscript.

\section{FUNDING}

COPSAC is funded by private and public research funds all listed on www.copsac.com. The Lundbeck Foundation; Danish Ministry of Health; Danish Council for Strategic Research; Danish Council for Independent Research and The Capital Region Research Foundation have provided core support for COPSAC. The funding agencies did not have any role in design and conduct of the study; collection, management, and interpretation of the data; or preparation, review, or approval of the manuscript. No pharmaceutical company was involved in the study.

\section{COMPETING INTEREST}

The authors declare no potential, perceived, or real conflict of interest regarding the content of this manuscript.

\section{FIGURE LEGENDS}

Figure 1: hs-CRP at age 7 years and concurrent allergy endpoints

Individual hs-CRP levels in children with (red) and without (blue) allergic sensitization

This article is protected by copyright. All rights reserved. 
phenotypes. Asymptomatic sensitization is sensitization without rhinitis, food reactions, asthma or eczema. Horisontal lines represent median values.

${ }^{*} \mathrm{p}<0.05 ;{ }^{* *} \mathrm{p}<0.01 ;$ sIgE=specific-IgE; SPT=skin prick test.

Figure 2: Principal component analysis of low-grade inflammatory biomarkers at age 7 years

Principal component analysis biplot showing the children's individual scores (grey dots) in the first principal component $\left(\mathrm{PC}_{1}\right)$ and second principal component $\left(\mathrm{PC}_{2}\right)$ as well as biomarker loadings for hs-CRP, IL-6, TNF- $\alpha$ and CXCL8 (red dots) and the correlation with allergy outcomes (blue dots). Percentages in parenthesis are the part of the total variation in the data set explained by the components.

sIgE=Specific-IgE; SPT=Skin prick test

\section{TABLES}

\section{Table 1: Baseline characteristics}

Child gender, household income, tobacco smoke exposure in the home, and recent infections in relation to hs-CRP level at age 7 years.

\begin{tabular}{|c|c|c|c|c|}
\hline \multirow{2}{*}{\multicolumn{2}{|c|}{ CHARACTERISTIC }} & \multirow{4}{*}{$\begin{array}{c}\begin{array}{c}\mathbf{N} \\
\text { (cases/total) }\end{array} \\
140 / 277 \\
137 / 277\end{array}$} & \multicolumn{2}{|c|}{$\begin{array}{c}\text { hs-CRP (mg/L) at age } 7 \\
\text { years }\end{array}$} \\
\hline & & & \multirow{2}{*}{$\begin{array}{c}\text { Median (IQR) } \\
1.92(0.82-6.56)\end{array}$} & \multirow{2}{*}{$\begin{array}{c}\text { P-value } \\
0.0004\end{array}$} \\
\hline \multirow[t]{2}{*}{ Gender } & Male & & & \\
\hline & Female & & $\begin{array}{c}4.02(1.82- \\
14.62)\end{array}$ & \\
\hline \multirow[t]{3}{*}{ Household income (yearly)* } & Low & $51 / 266$ & $3.50(1.63-8.74)$ & \multirow[t]{3}{*}{0.55} \\
\hline & Average & $51 / 266$ & $\begin{array}{c}3.67(1.03- \\
18.37)\end{array}$ & \\
\hline & High & $164 / 266$ & $2.86(1.21-7.50)$ & \\
\hline \multirow[t]{2}{*}{$\begin{array}{l}\text { Smoke exposure in the } \\
\text { home }\end{array}$} & Yes & $96 / 271$ & $\begin{array}{c}3.10(1.50- \\
12.96)\end{array}$ & \multirow[t]{2}{*}{0.15} \\
\hline & No & $175 / 271$ & $2.73(1.05-7.55)$ & \\
\hline \multirow[t]{2}{*}{$\begin{array}{l}\text { Infection } 14 \text { days before hs- } \\
\text { CRP assessment }{ }^{* *}\end{array}$} & Yes & $24 / 277$ & $\begin{array}{l}24.19(4.32- \\
33.51)\end{array}$ & \multirow[t]{2}{*}{$<0.0001$} \\
\hline & No & $253 / 277$ & $2.73(1.16-7.50)$ & \\
\hline
\end{tabular}

*Yearly household income: low $(<53.000 €)$, medium (53.000-80.000 €), high $(>80.000$ $€)$.

${ }^{* *}$ Infections include any upper or lower respiratory tract infection, gastroenteritis or fever with unknown cause within 14 days before the blood sampling for hs-CRP measurement. 
Table 2: Inflammatory biomarkers at age 7 years vs. allergy-associated end-points

Association analyses between markers of low-grade inflammation (hs-CRP, IL-6, TNF- $\alpha$, CXCL8) and concurrent allergic sensitization phenotypes. Analyses are adjusted for gender, infections 14 days prior to biomarker assessment and CRP genetic risk-score.

\begin{tabular}{|c|c|c|c|c|c|c|c|c|}
\hline \multirow{2}{*}{$\begin{array}{l}\text { Outcome } \\
\text { (cases/total) }\end{array}$} & \multicolumn{2}{|c|}{ Log-hs-CRP } & \multicolumn{2}{|c|}{ Log-IL-6 } & \multicolumn{2}{|c|}{ Log-TNF- $\alpha$} & \multicolumn{2}{|c|}{ Log-CXCL8 } \\
\hline & $\begin{array}{c}\text { OR } \\
(95 \% \\
\mathrm{CI}) \\
\end{array}$ & $\mathrm{p}$ & $\begin{array}{c}\text { OR } \\
(95 \% \\
\text { CI) }\end{array}$ & $\mathrm{p}$ & $\begin{array}{c}\text { OR } \\
(95 \% \\
\mathrm{CI})\end{array}$ & $\mathrm{p}$ & $\begin{array}{c}\text { OR } \\
(95 \% \\
\text { CI) }\end{array}$ & $\mathrm{p}$ \\
\hline \multicolumn{9}{|l|}{ Any sensitization } \\
\hline $\operatorname{sigE}(80 / 260)$ & $\begin{array}{c}1.40 \\
(1.14- \\
1.72)\end{array}$ & 0.001 & $\begin{array}{c}1.09 \\
(0.78- \\
1.53)\end{array}$ & 0.62 & $\begin{array}{c}1.70 \\
(0.80- \\
3.65)\end{array}$ & 0.17 & $\begin{array}{c}1.18 \\
(0.80- \\
1.74)\end{array}$ & 0.41 \\
\hline $\begin{array}{l}\text { Skin prick test } \\
(43 / 244)\end{array}$ & $\begin{array}{c}1.50 \\
(1.18- \\
1.92)\end{array}$ & 0.001 & $\begin{array}{c}1.19 \\
(0.77- \\
1.83)\end{array}$ & 0.44 & $\begin{array}{c}2.84 \\
(0.82- \\
9.88)\end{array}$ & 0.10 & $\begin{array}{c}1.07 \\
(0.60- \\
1.92)\end{array}$ & 0.82 \\
\hline \multicolumn{9}{|c|}{ Aeroallergen sensitization } \\
\hline sIgE (68/239) & $\begin{array}{r}1.43 \\
(1.15- \\
1.77)\end{array}$ & 0.001 & $\begin{array}{c}1.02 \\
(0.71- \\
1.48)\end{array}$ & 0.91 & $\begin{array}{c}2.43 \\
(0.87- \\
6.83)\end{array}$ & 0.09 & $\begin{array}{c}1.13 \\
(0.74- \\
1.72)\end{array}$ & 0.57 \\
\hline $\begin{array}{l}\text { Skin prick test } \\
(41 / 244)\end{array}$ & $\begin{array}{c}1.49 \\
(1.16- \\
1.90)\end{array}$ & 0.002 & $\begin{array}{c}1.16 \\
(0.75- \\
1.80)\end{array}$ & 0.51 & $\begin{array}{c}2.72 \\
(0.77- \\
9.63)\end{array}$ & 0.12 & $\begin{array}{c}1.08 \\
(0.60- \\
1.95)\end{array}$ & 0.81 \\
\hline \multicolumn{9}{|c|}{ Food sensitization } \\
\hline $\operatorname{sIgE}(48 / 219)$ & $\begin{array}{c}1.31 \\
(1.02- \\
1.67)\end{array}$ & 0.04 & $\begin{array}{c}1.11 \\
(0.71- \\
1.73)\end{array}$ & 0.65 & $\begin{array}{c}1.23 \\
(0.54- \\
2.80)\end{array}$ & 0.62 & $\begin{array}{c}1.25 \\
(0.76- \\
2.07)\end{array}$ & 0.38 \\
\hline $\begin{array}{l}\text { Skin prick test } \\
(8 / 244)\end{array}$ & $\begin{array}{c}1.66 \\
(1.05- \\
2.63) \\
\end{array}$ & 0.03 & $\begin{array}{c}1.40 \\
(0.54- \\
3.64) \\
\end{array}$ & 0.49 & $\begin{array}{c}0.73 \\
(0.05- \\
10.68)\end{array}$ & 0.82 & $\begin{array}{c}1.52 \\
(0.47- \\
4.93) \\
\end{array}$ & 0.49 \\
\hline \multicolumn{9}{|c|}{ Asymptomatic sensitization $^{1}$} \\
\hline $\operatorname{sIgE}(34 / 260)$ & $\begin{array}{c}1.40 \\
(1.06- \\
1.85)\end{array}$ & 0.02 & $\begin{array}{c}0.87 \\
(0.52- \\
1.48) \\
\end{array}$ & 0.51 & $\begin{array}{c}1.20 \\
(0.46- \\
3.10)\end{array}$ & 0.71 & $\begin{array}{c}1.18 \\
(0.66- \\
2.07)\end{array}$ & 0.59 \\
\hline $\begin{array}{l}\text { Skin prick test } \\
(8 / 244)\end{array}$ & $\begin{array}{c}1.70 \\
(1.07- \\
2.70)\end{array}$ & 0.03 & $\begin{array}{c}0.91 \\
(0.30- \\
2.81)\end{array}$ & 0.87 & $\begin{array}{c}3.48 \\
(0.24- \\
51.31)\end{array}$ & 0.36 & $\begin{array}{c}0.37 \\
(0.06- \\
2.25)\end{array}$ & 0.28 \\
\hline $\begin{array}{l}\text { Allergic rhinitis } \\
(34 / 256)\end{array}$ & $\begin{array}{c}1.36 \\
(1.05- \\
1.76)\end{array}$ & 0.02 & $\begin{array}{c}1.56 \\
(0.97- \\
2.53)\end{array}$ & 0.07 & $\begin{array}{c}1.62 \\
(0.56- \\
4.70)\end{array}$ & 0.37 & $\begin{array}{c}1.05 \\
(0.62- \\
1.78)\end{array}$ & 0.86 \\
\hline Asthma & $\begin{array}{r}1.37 \\
(1.03- \\
1.84) \\
\end{array}$ & 0.03 & $\begin{array}{c}1.25 \\
(0.70- \\
2.22) \\
\end{array}$ & 0.46 & $\begin{array}{c}1.97 \\
(0.53- \\
7.36) \\
\end{array}$ & 0.31 & $\begin{array}{c}1-68 \\
(0.81- \\
3.50) \\
\end{array}$ & 0.16 \\
\hline log-Total-IgE2 & $\begin{array}{c}0.15 \\
(0.03- \\
0.26)\end{array}$ & 0.01 & $\begin{array}{c}0.13 \\
(-0.08- \\
0.33)\end{array}$ & 0.23 & $\begin{array}{c}0.13 \\
(-0.26- \\
0.52)\end{array}$ & 0.52 & $\begin{array}{c}0.01 \\
(-0.22- \\
0.24)\end{array}$ & 0.94 \\
\hline
\end{tabular}

${ }^{1}$ Asymptomatic sensitization is any sensitization without concurrent rhinitis, clinical food reaction, asthma or eczema. 
${ }^{2}$ Linear model. Estimate is $\beta$-coefficient (95\% CI).

Table 3: Principle component analysis of allergy-associated end-points at age 7 years

Principle component association analysis between first principle component $\left(\mathrm{PC}_{1}\right)$, second principle component $\left(\mathrm{PC}_{2}\right)$, and allergic sensitization phenotypes.

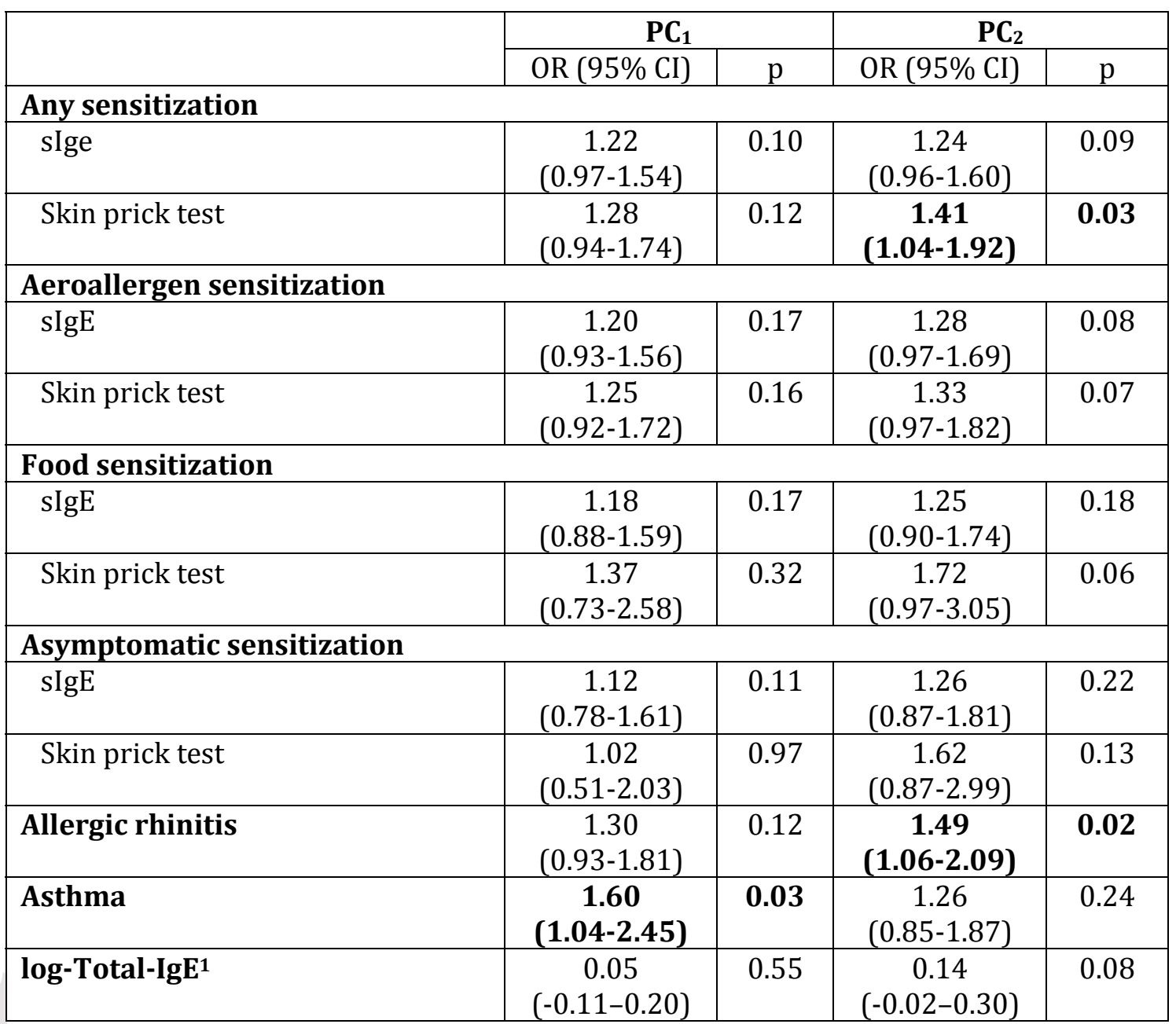

${ }^{1}$ Linear model. Estimate is $\beta$-coefficient $(95 \% \mathrm{CI})$.

This article is protected by copyright. All rights reserved. 
hs-CRP level by allergy outcome

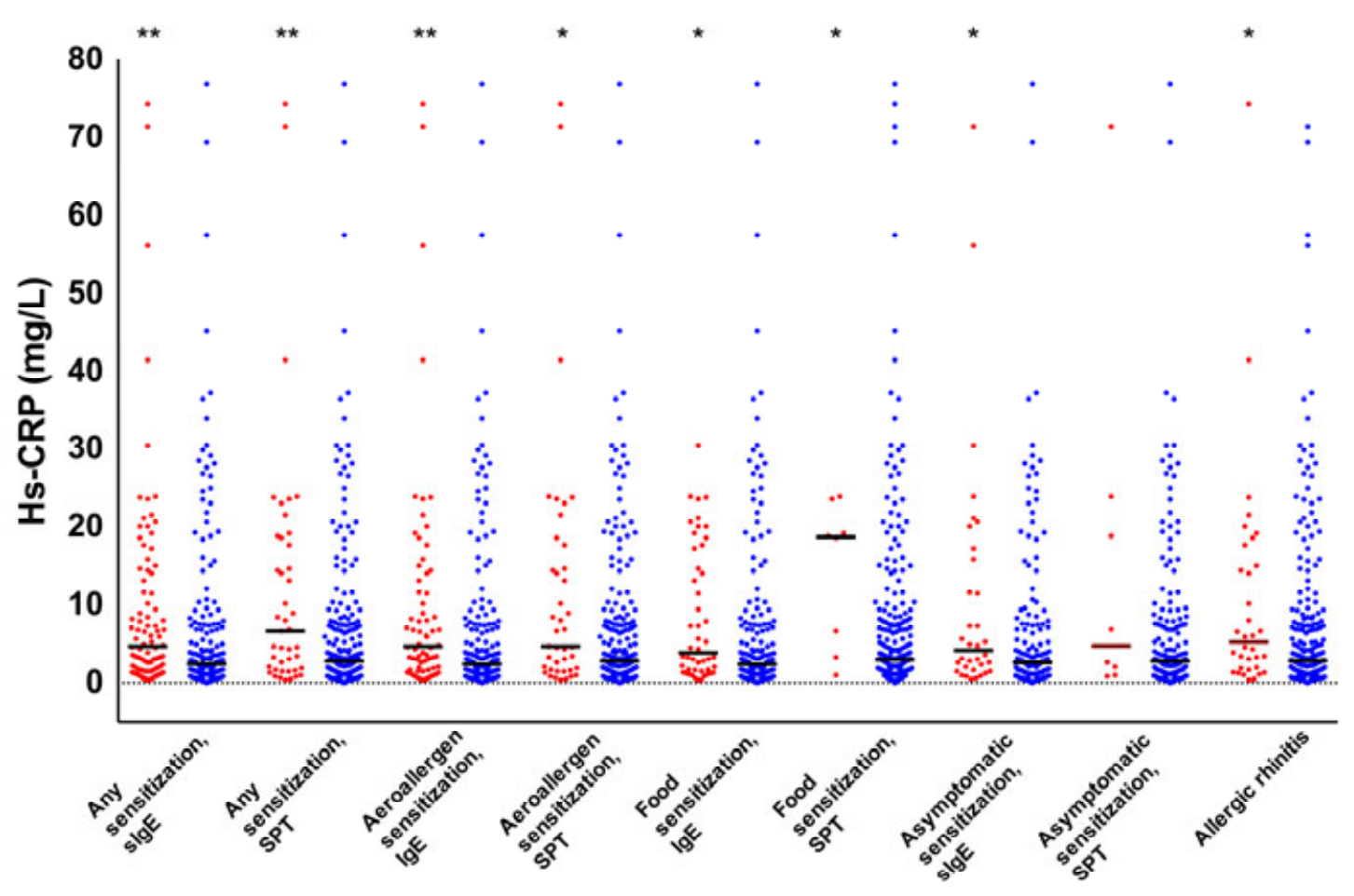

This article is protected by copyright. All rights reserved. 


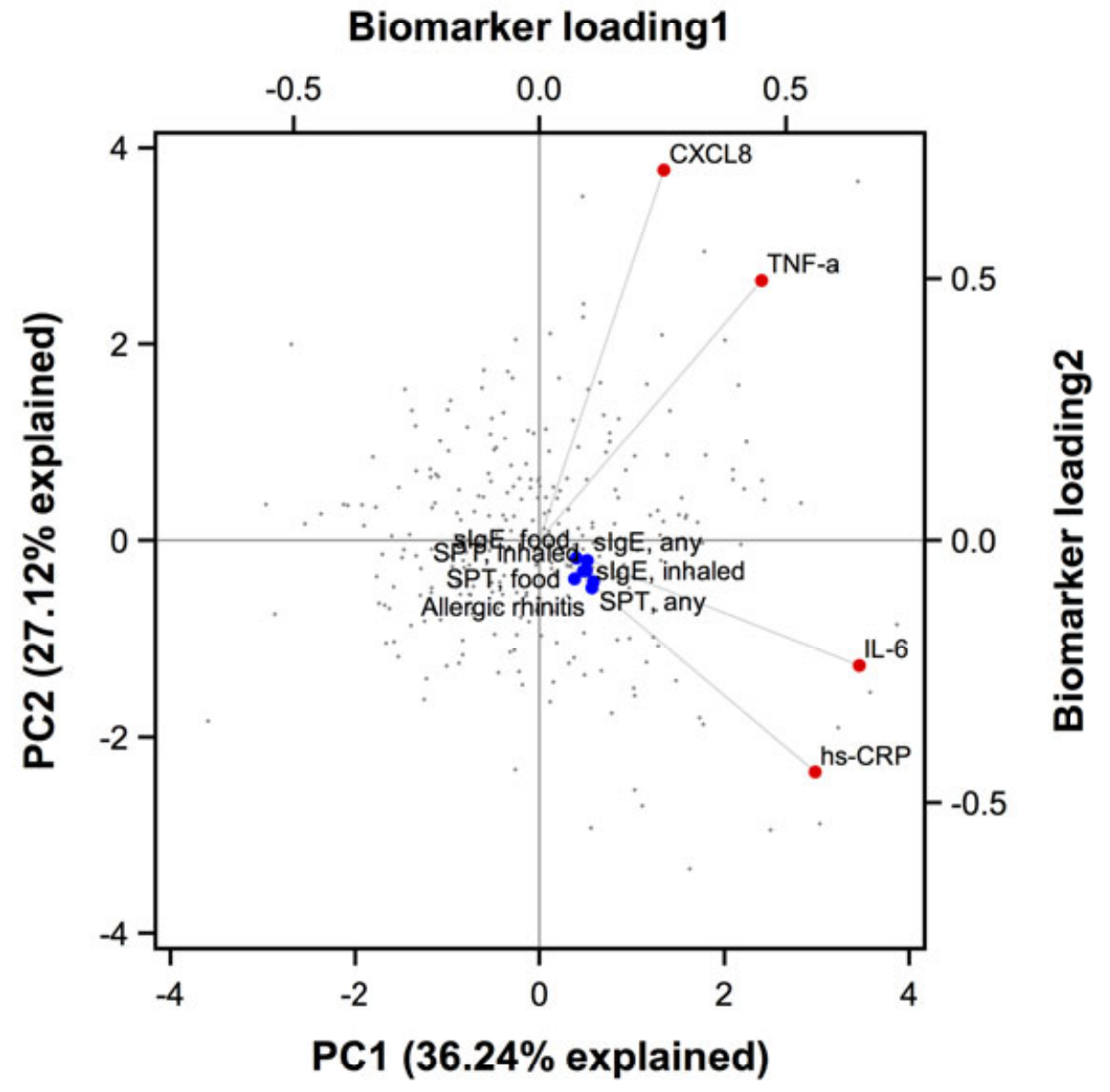

This article is protected by copyright. All rights reserved. 